\title{
MiR-142-3p Inhibits TGF- $\beta 3$-Induced Blood-Testis Barrier Impairment by Targeting Lethal Giant Larvae Homolog 2
}

\author{
Ying Xu Weixing Wu Yunxia Fan Shuyi Jiang Xiaoyu Jia Wenhui Su \\ Department of Biochemistry and Molecular Biology, College of Basic Medical Science, China Medical \\ University, Shen Yang, China
}

\section{Key Words}

BTB $•$ MiR-142-3p • TGF- $\beta 3 \cdot$ Lgl2 • Seminiferous epithelial cycle

\begin{abstract}
Background/Aims: Transforming growth factor- $\beta 3$ (TGF- $\beta 3$ ) has been proved to perturb the blood-testis barrier (BTB) by accelerating junction protein endocytosis in Sertoli cells (SCs) to accommodate the traversing of preleptotene spermatocytes across the BTB around stage VIII in rat. Yet the molecular network underlying the impairment of TGF- $\beta 3$ on BTB integrity is not fully elucidated. Our study herein was designed to investigate the participation of microRNA$142-3 p$ (miR-142-3p), which has been reported to affect TGF- $\beta 3$ signaling via different pathways, during BTB dynamics and the corresponding mechanisms. Methods: MiRNA mimic or agomiRNA was co-administered with or without TGF- $\beta 3$ in the cultured SCs or in the rat testis. The SC permeability barrier function was reflected by measuring the transepithelial resistance (TER) and the permeability of the sodium fluorescein ( $\mathrm{Na}-\mathrm{F})$. The BTB integrity was detected by the permeation of biotin. A luciferase reporter assay was used to testify the potential target of miR-142-3p, lethal giant larvae 2 (Lgl2). Laser capture microdissection (LCM) was applied to acquire cell components of different stages of seminiferious tubules, followed by detection of the expression levels of miR-142-3p, TGF- $\beta 3$, and Lgl2 by qPCR. The SC barrier function was also detected as above in the presence of TGF- $\beta 3$ after Lgl2 knockdown. Results: We revealed a reversion of TGF- $\beta 3$-induced BTB impairment after miR$142-3 p$ treatment both in vitro and in vivo. Meanwhile, the activation of Cdc42 and reduction in occludin aroused by TGF- $\beta 3$ were also reversed by miR-142-3p. The predicted binding of miR-142-3p with $3^{\prime}$-untranslated region ( $3^{\prime}$-UTR) of $L g \mid 2$, was verified by the luciferase assay. Moreover, an increased Lgl2 level in TGF- $\beta 3$-treated SCs was found and correlated stagespecific expressions of TGF- $\beta 3$, miR-142-3p, and Lgl2 were revealed. Knockdown of Lgl2 in SCs was shown to partially antagonize the BTB disruption mediated by TGF- $\beta 3$. Conclusions: Collectively, our results suggest a resistance of miR-142-3p on the BTB impairment caused by TGF- $\beta 3$ during the seminiferous epithelial cycle by targeting Lgl2.

Department of Biochemistry and Molecular Biology, College of Basic Medical Science China Medical University, No. 77 Puhe Road, Shenyang North New Area, Shenyang (China), Tel. +86-18900910455, E-Mail whsu@cmu.edu.cn 


\section{Cellular Physiology Cell Physiol Biochem 2018;46:253-268

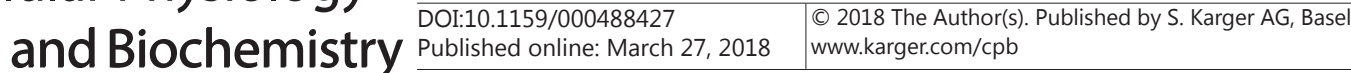

Xu et al.: MiR-142-3p Inhibits TGF- 33 in BTB Regulation

\section{Introduction}

In the mammalian seminiferous epithelium, Sertoli cells (SCs) stretch from the basement to the lumen side of the seminiferous tubule and keep immediate association with germ cells of different development stages. As one of the primary somatic components of the testis, SCs exert a momentous role in spermatogenesis that guarantees the sustaining generation of gamete in adult males. Mature SCs that cease dividing after puberty not only provide germ cells with nutritional and structural support, but also form the blood-testis barrier (BTB) at adjacent SC junctions, enabling meiosis and the following spermatocyte differentiation to take place in an independent environment [1]. Thus, the functional integrity of the BTB that mainly contributed by tight junctions (TJs) between SCs is of great importance for spermatogenesis and male fertility. It has been demonstrated in various epithelia, including the BTB, the function of TJ was regulated by cytokines under physiological or pathological conditions [2-6], such as transforming growth factors (TGFs), tumor necrosis factors (TNFs) and interleukins (ILs). Among these factors, TGF- $\beta 3$ was reported to induce BTB damage by enhancing endocytosis and intracellular degradation of TJ integral proteins [7, 8], which destabilized the BTB to facilitate the transit of preleptotene spermatocyte at stage VIII in the rat testis $[9,10]$. TGF- $\beta 3$ is a $25-\mathrm{kDa}$ homodimeric glycoprotein secreted stage-specifically by SCs and spermatocytes/spermatids in the testis. It exerts its biological roles by binding sequentially with TGF- $\beta$ type II receptor (T $\beta$ RII) and type II receptor (T $\beta$ RII) to form TGF- $\beta / T \beta R I I / T \beta R I I$ complex, which then recruits other adaptors and mediates different downstream pathways [11]. Although some signaling molecules, such as p38 mitogen activated protein kinase (MAPK) and Cdc42, have been determined to be crucial in the TGF$\beta 3$-induced cascade during BTB disruption $[8,12]$, the overall molecular network related to TGF- $\beta 3$-regulated BTB dynamics remains largely uncovered.

Gene expression regulation on post-transcriptional level plays a key role during spermatogenesis [13]. MicroRNA-mediated post-transcriptional regulation was indispensable for germ cell development and male fertility [14]. For example, selective ablation of Dicer, the RNaseIII endonuclease required for microRNA biogenesis, in mouse SCs resulted in infertility due to spermatozoa absence, testicular degeneration [15], or major alterations in the testicular proteome [16]. A recent study also reported DICER-dependent pathways in control of the organization of cell junctions in the seminiferous epithelium through cell adhesion-related genes such as claudin 5 [17]. However, little research has been carried out to investigate the possible roles of miRNAs in regulation of the BTB function until now. MiR-142-3p, first identified to exert its function during the development of the lymphoid system [18], was subsequently proved to regulate cell differentiation and serve as a potential tumor suppressor in acute myeloid leukemia, hepatocellular carcinoma, osteosarcoma, nasopharyngeal carcinoma, and pancreatic ductal adenocarcinoma, etc [1924]. Nevertheless, the microarray using human testis samples showed a relatively high expression level of miR-142-3p but with no significant variation between normal adult testis and testicular tumors [25]. What interests us was the participation of miR-142-3p in TGF$\beta$-regulated signaling pathways. For example, during region-dependent-chondrogenesis, miR-142-3p was involved in the limb type-specific effect of TGF- $\beta 3$ on mesenchymal cells by modulating transcription of a disintegrin and metalloprotease (ADAM) [26]. In vascular smooth muscle cells (VSMCs), TGF- $\beta$ could induce the expression of miR-142-3p, which inhibited cell migration and determined contractile phenotype of VSMCs by targeting at dedicator of cytokinesis 6 (DOCK6) [27]. On the other hand, miR-142-3p was revealed to directly bind to 3'-UTR of T $\beta$ RII and suppress expression of T $\beta$ RII mRNA and protein, leading to repression of TGF- $\beta$-induced growth inhibition in non-small cell lung cancer (NSCLC) [28]. These reports implied the complicated interactions between miR-142-3p and TGF- $\beta$ signaling. Based on these, we sought to investigate whether miR-142-3p played a role during the BTB dynamics regulated by TGF- $\beta 3$ in the present study.

Lethal giant larvae ( $\mathrm{Lgl})$ gene encodes a protein containing sequences similar to several junction proteins, which constitutes the Scribble polarity complex together with Scribble 


\section{Cellular Physiology Cell Physiol Biochem 2018;46:253-268

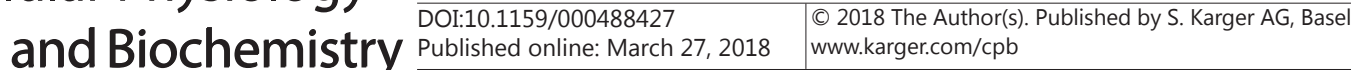

Xu et al.: MiR-142-3p Inhibits TGF- $\beta 3$ in BTB Regulation

and discs large (Dlg) [29]. In Drosophila epithelia, the three components of Scribble complex located at the basolateral side act together with the apical partitioning defective (Par) complex to regulate apical-basal polarity and also act as tumor suppressor genes [30, 31]. Until now, four mammalian homologs of Lgl are recognized, with Lgl2 being the predominant form in the testis. During spermatogenesis, the Scribble/Lgl2/Dlg1 complex was previously proved to regulate spermatid polarity and BTB integrity by reorganizing actin filament network and affecting junction protein localization [32]. Herein, we identified Lgl2 as the direct target of miR-142-3p, discovered the stage-specific expression of Lgl2 and miR-142-3p, and demonstrated the down-regulation of Lgl2 expression by miR-142-3p could antagonize the TGF- $\beta 3$-induced BTB destabilization both in cultured SCs and during the seminiferous epithelial cycle in vivo. These findings support the notion that non-coding RNAs could cooperate with cytokines in the regulation of BTB dynamics during the seminiferous epithelial cycle.

\section{Materials and Methods}

\section{Animal treatment and antibodies}

The 90-day- and 20-day-old male Sprague-Dawley rats were provided by the Department of Laboratory Animals of China Medical University (CMU) and raised at $20-22^{\circ} \mathrm{C}$ with accessible standard fodder and water in a dark/light cycle of $12 \mathrm{~h} / 12 \mathrm{~h}$. All the animals were treated humanely to alleviate discomfort and distress, and the protocol for animal handling was approved by the Animal Care and Use Committee of CMU. In the in vivo experiments, adult male rats weighing 250-280 g were treated with $1 \mathrm{nmol}$ of micrON ${ }^{T M}$ rnomiR-142-3p agomir or micrON ${ }^{T M}$ agomir Negative Control (RiboBio Company, Guangzhou, China), which was diluted in $50 \mu \mathrm{l}$ RNase free saline, via multiple-site intratesticular (i.t.) injection using a 28-gauge needle as described for 3 consecutive days [33]. After 48 hours, a single dose of $200 \mathrm{ng}$ of human recombinant TGF- $\beta 3$ (PeproTech, Rocky Hill, NJ, USA) diluted in $50 \mu \mathrm{l}$ PBS (10 mM sodium phosphate, $0.15 \mathrm{mM} \mathrm{NaCl}, \mathrm{pH} 7.4$ ), which was previously proved to yield distinguishable and reversible damage at the BTB, was administered via i.t. injection. $24 \mathrm{~h}$ later, animals were subjected to BTB integrity assay or terminated by inhalation of excessive ether for testes isolation.

The antibodies used for IP, Western blot, immunofluorescence analysis were as follows: occludin (Invitrogen, Carsland, CA, USA), GTP-CDC42 (NewEast Biosciences, King of Prussia, PA, USA), CDC42 (Cell Signaling, Danvers, MA, USA), Lgl2 (Abcam, Cambridge Science Park, British), TßRI (Santa Cruz Biotechnology, Santa Cruz, CA, USA), GAPDH (Santa Cruz Biotechnology), HRP-conjugated bovine anti-rabbit IgG (Santa Cruz Biotechnology), and Alexa Fluor 488- or 555- conjugated secondary antibodies (Invitrogen). Different dilution ratios were selected according to the manufactures' specifications.

\section{BTB integrity assay in vivo}

The integrity of the BTB was evaluated by using EZ-Link Sulfo-NHS-LC-Biotin (Pierce Biotechnology, Rockford, IL, USA) as an indicator as described previously [34-36]. In brief, after TGF- $\beta 3$ treatment, three or four rats from each group were anesthetized by ketamine $\mathrm{HCl}(100 \mathrm{mg} / \mathrm{kg})$ via i.p. and the testes were then exposed. Then a small opening was created with ophthalmic forceps on the testis tunica, and $50 \mu \mathrm{l}$ Sulfo-NHS-LC-Biotin $(10 \mathrm{mg} / \mathrm{ml})$ freshly dissolved in PBS containing $1 \mathrm{mM} \mathrm{CaCl}_{2}$ was injected into the testis interstitium. The other testis was injected with isometric PBS vehicle as a control. After $30 \mathrm{~min}$ for biotin diffusion, the rats were terminated by $\mathrm{CO}_{2}$ asphyxiation and the testes were immediately removed and frozen in liquid nitrogen. Then $10 \mu \mathrm{m}$ cryosections were prepared and fixed in $4 \%$ paraformaldehyde for 5 min before being blocked with $5 \%$ bovine serum albumin. Afterwards, the sections were incubated with Alexa Fluor 568-conjugated streptavidin (Invitrogen) for $1 \mathrm{~h}$ at room temperature, which were finally analyzed by fluorescence microscopy after mounting with Prolong Gold Antifade reagent (Invitrogen). The permeability of the BTB was reflected by the diffusion distance of biotin from the basal membrane to the tubule lumen, which was semi quantitatively calculated by plotting the diffusion distance with the average radius of each tubule. In each group, at least 60-80 tubules randomly selected from three or four rats were analyzed. Positive controls were established by treating rats with a single dose of $5 \mathrm{mg} / \mathrm{kg} \mathrm{CdCl}$, a known disruptor of the BTB, via i.p. 3 days before the BTB integrity assay. 


\section{Cellular Physiology Cell Physiol Biochem 2018;46:253-268 \begin{tabular}{l|l} 
and Biochemistry Published online: March 27, 2018 & $\begin{array}{l}\text { (c) } 2018 \text { The Author(s). Published by S. Karger AG, Basel } \\
\text { www.karger.com/cpb }\end{array}$
\end{tabular}}

Xu et al.: MiR-142-3p Inhibits TGF- $\beta 3$ in BTB Regulation

\section{Primary Sertoli cell culture, transient transfection, and TGF- $\beta 3$ treatment}

To acquire well-purified mature SCs with less germ cells, 20-day-old rats were used for SCs isolation according to a classical method as described [36, 37]. After isolation, the SCs were plated at different densities on Matrigel (BD BioSciences, Franklin Lakes, NJ, USA)-coated culture dishes according to the following detections: $0.5 \times 10^{6} / \mathrm{cm}^{2}$ on 6 -well plates for immunoblot and immunoprecipitation, $1.2 \times 10^{6} / \mathrm{cm}^{2}$ on Millicell-HA inserts (Millipore, Boston, MA, USA) for SC epithelial permeability barrier assessment, and $0.05 \times 10^{6} / \mathrm{cm}^{2}$ on cover glass for immunofluorescence analysis. The primary SCs were cultured at $35^{\circ} \mathrm{C}$ for 7 days in a humid atmosphere with $5 \% \mathrm{CO}_{2}$ using serum-free DMEM/F12 (Gibco, Grand Island, NY, USA) containing $10 \mu \mathrm{g} / \mathrm{ml}$ insulin, $5 \mu \mathrm{g} / \mathrm{ml}$ transferrin, $2.5 \mathrm{ng} / \mathrm{ml}$ epidermal growth factor, and $5 \mu \mathrm{g} / \mathrm{ml}$ bacitracin. To eliminate the residual germ cells, SCs were subjected to a hypotonic Tris solution (10 mM, pH7.4) for 2 min at room temperature on culture day 2 to achieve a purity of more than $98 \%$.

In experiments to detect the influence of miR-142-3p on BTB compromise induced by TGF- $\beta 3$, SCs were transfected with micrON ${ }^{\top M}$ rno-miR-142-3p mimic or micrON ${ }^{\top M}$ mimic negative control (RiboBio Company) using Lipofectamine2000 transfection system (Thermo Fisher Scientific, Waltham, MA, USA) on culture day 3 for $24 \mathrm{~h}$, with siGLO red (Dharmacon, Carsland, CA, USA) as the transfection indicator. On day 5 , transfected SCs were treated with $3 \mathrm{ng} / \mathrm{ml}$ TGF- $\beta 3$ for another $24 \mathrm{~h}$.

To detect the regulation of miR-142-3p on Lgl2 expression, SCs were transfected with miR-142-3p mimic, or miR-142-3p inhibitor (RiboBio Company), or the corresponding negative control on day 3 for 24 $\mathrm{h}$ using Lipofectamine2000 before cell lysates were prepared for immunoblot or qPCR analysis.

SiRNAs specifically targeting rat Lgl2 were designed and synthesized by GenePharma, which were subjected to BLAST to ensure no homology with other genes. In experiments to detect the role of Lgl2 during BTB compromise induced by TGF- $\beta 3$, SCs were transfected with Lgl2 siRNA (sense: 5'-CCAUCAGUUCAGACGAGGUtt-3', antisense: 5'-ACCUCGUCUGAACUGAUGGtt-3') or scrambled control siRNA (sense: 5'-GGUCGAGUCAUCAGACCAUtt-3', antisense: 5'-AUGGUCUGAUGACUCGACCtt-3') using Lipofectamine 2000 on cultured day 3 for $24 \mathrm{~h}$, with siGLO red (Dharmacon) as the transfection indicator. On day 5, transfected SCs were treated with $3 \mathrm{ng} / \mathrm{ml}$ TGF- $\beta 3$ for another $24 \mathrm{~h}$.

\section{Sertoli cell epithelial barrier permeability assessment}

The SCs plated on the Matrigel-coated Millicell inserts in each group form an intact epithelium. The barrier function could be evaluated by its resistance to the passage of an electrical current between the apical and basal chamber of the bi-cameral unit, which was measured by using a Millicell ERS-2 Epithelial Volt-Ohm Meter at specified time points. In each experiment, three paralleled wells were established for each group and the SC-free units were set as the blank control. The trans-epithelial resistance (TER) value $\left(\Omega \mathrm{cm}^{2}\right)$ of each group at designated time points was calculated as $\left(\mathrm{R}_{\text {unknown }}-\mathrm{R}_{\text {blank }}\right) \times \mathrm{S}$, in which "S" refers to the surface area of the Millicell insert $\left(\mathrm{cm}^{2}\right)$.

The permeability of the SC epithelium was also assessed by sodium fluorescein (Na-F), an indicator of $376 \mathrm{kDa}$. Briefly, the culture medium of the bicameral unit was replaced by the permeability assay buffer (pH 7.4, containing $10 \mathrm{mM}$ HEPES, and $25 \mathrm{mM}$ glucose, $136 \mathrm{mM} \mathrm{NaCl}, 10 \mathrm{mM} \mathrm{NaH} \mathrm{PO}_{4}, 2.7 \mathrm{mM} \mathrm{KCl}, 1.5 \mathrm{mM}$ $\mathrm{KH}_{2} \mathrm{PO}_{4}, 0.9 \mathrm{mM} \mathrm{CaCl}_{2}, 0.5 \mathrm{mM} \mathrm{MgCl}$ ) and an additional $10 \mu \mathrm{g} / \mathrm{ml} \mathrm{Na-F}$ was added in the upper chamber before incubation at $35^{\circ} \mathrm{C}$ for $1 \mathrm{~h}$. Then $50 \mu \mathrm{l}$ samples were obtained from basal chambers for Na-F emission detection at $535 \mathrm{~nm}$. In each experiment, the deduced Na-F concentration in the basal chamber of the control group before treatment was arbitrarily set as $100 \%$.

\section{Lysate preparation, immunoprecipitation and immunoblot analysis}

In this study, lysates of SCs, testis homogenate, or samples from LCM (as described below) of different groups were prepared in fresh IP lysis buffer (pH 7.4, containing $50 \mathrm{mM}$ Tris, $150 \mathrm{mM} \mathrm{NaCl}, 2$ $\mathrm{mM}$ phenylmethylsulphonyl fluoride, $1 \mathrm{mM}$ sodium orthovanadate, $2 \mathrm{mM}$ EGTA, 10\% glycerol, $2 \mathrm{mM}$ $\mathrm{N}$-ethylmaleimide, $1 \%$ Nonidet $\mathrm{P}-40$ plus protease and phosphatase inhibitors). Supernatants were retrieved and stored at $-80^{\circ} \mathrm{C}$ after ultrasonication and centrifugation at $15000 \mathrm{~g}$ for $1 \mathrm{~h}$. The protein concentration of each sample was determined by the Bio-Rad DC Protein assay kit (Bio-Rad Laboratories, Hercules, CA, USA). After denaturation at $100^{\circ} \mathrm{C}$ for $5 \mathrm{~min}$, approximately $40 \mu \mathrm{g}$ protein from testis homogenate or 20 $\mu \mathrm{g}$ protein from SC lysates were applied per lane and resolved by SDS-PAGE, followed by transferring and immunoblotting sequentially with specific primary and secondary antibodies. Then the enhanced chemiluminescence kit (Pierce Chemical Company, Appleton, WI, USA) was applied to observe the protein 


\section{Cellular Physiology Cell Physiol Biochem 2018;46:253-268 \begin{tabular}{l|l} 
and Biochemistry & DOI:10.1159/000488427 \\
\hline Published online:March 27, 2018 & $\begin{array}{l}\text { ( 2018 The Author(s). Published by S. Karger AG, Basel } \\
\text { www.karger.com/cpb }\end{array}$
\end{tabular}}

Xu et al.: MiR-142-3p Inhibits TGF- $\beta 3$ in BTB Regulation

bands under the ChemiDoc XRS imaging system (Bio-Rad, Hercules, CA, USA). Further image intensity analysis was performed using Scion Image software (version 4.0.3). The level of GAPDH was also detected in each experiment, serving as the protein loading control, against which each data point was normalized.

In the experiments to detect the GTPase activity of Cdc42, $500 \mu$ g protein lysate of each sample after preclearance by protein G magnetic beads (GE Healthcare, Waukesha, WI, USA) was added with $2 \mu \mathrm{g}$ of specific monoclonal anti-GTP-Cdc42 antibody and incubated overnight at room temperature with constant rotation. Then $20 \mu \mathrm{l}$ of protein $\mathrm{G}$ beads was added to precipitate the immunocomplex for $2 \mathrm{~h}$ with constant rotation, which was gently washed in fresh IP lysis buffer after centrifugation. Following denaturation at $100^{\circ} \mathrm{C}$ for $5 \mathrm{~min}$ in the SDS-sample buffer, the immunocomplex was resolved by SDS-PAGE and subjected to immunoblot using anti-Cdc42 antibody.

\section{Immunofluorescence analysis}

The primary SCs cultured on coverslips or frozen sections of testis prepared on poly-L-lysine-coated slides after different treatments were respectively fixed in 4\% paraformaldehyde or Bouin's fixative for 5 min. Cells or sections were then permeabilized with $0.1 \%$ Triton X-100 (in PBS) for 4 min before blocking with $5 \%$ bovine serum albumin (BSA, in PBS) for 30 min. Afterwards, cells or sections were incubated with a rabbit anti-occludin antibody (1:100) diluted in PBS containing 1\% BSA overnight, followed by incubation with Alexa Fluor 488 or 555-conjugated donkey anti-rabbit IgG (1:150) at room temperature for $1 \mathrm{~h}$. The nuclei were stained with $0.5 \mu \mathrm{g} / \mathrm{ml}$ DAPI (Beyotime Institute of Biotechnology, Shanghai, China) for $10 \mathrm{~min}$. At last, the cultured SCs or sections were observed using an Olympus BX60 fluorescence microscope after mounting. Images from one experiment were captured by a SpotRT digital camera using the same exposure time.

\section{Luciferase reporter assay}

To testify the potential binding of miR-142-3p with Lgl2 predicted by TargetScan (http://www. targetscan.org), a fragment of 186 bp containing the predicted binding site of the Lgl2 3'-untranslated region (3'-UTR) was amplified (forward primer: 5'-ccggagctcggggacatcatccaggctg-3', reverse primer: 5'-cgaaagcttgacattgataaaaggatca-3') and then cloned to the $3^{\prime}$ end of the luciferase reporter gene in pMIRREPORT vector (Ambion, Carlsbad, CA, USA) with SacI and HindIII (underlined sequence) to generate the Lgl2-3'UTR-wild type (WT). The corresponding Lgl2-3'UTR-mutant (MUT) was generated using the Easy Mutagenesis System Kit (TransGen Biotech, Peking, China). Afterwards, HEK293 cells were plated and cultured to a 70\% confluence in DMEM/F12 before a co-transfection of the Lgl2-3'UTR-WT (or Lgl2-3'UTRMUT) and miR-142-3p mimic (or scrambled miR-NC mimic). Cells were collected $48 \mathrm{~h}$ later and the luciferase activity was measured with the Dual-Luciferase Reporter Assay Kit (Promega). The relative firefly luciferase activity was obtained following normalizing the firefly luciferase activity against renilla luciferase activity.

\section{Histology staining and laser capture microdissection (LCM)}

All procedures of testis section preparation, staining and LCM for seminiferous epithelia of different stages were performed in an RNase-free condition according to method described by Catlin et al. with minor modifications to generate enough amount of high-quality RNA [38]. To be specific, testes of mature SD rats were removed after termination and frozen in liquid nitrogen immediately. Then $10 \mu \mathrm{m}$ sections were made using the Leica CM1900 Cryostat (Leica Biosystems, Germany) at $-20^{\circ} \mathrm{C}$ after embedding the tissue with Tissue-Tek® O.C.T. Compound (Sakura, USA). The testis sections were softly moved onto PEN foil slides, which were then kept in the cryostat hood for 2 min for drying. After fixation in $70 \%$ ethanol for $30 \mathrm{~s}$, the sections were stained with hematoxylin for $30 \mathrm{~s}$ at room temperature, washed with nuclease-free water for $30 \mathrm{~s}$ and then subjected to sequential dehydration with 75\% ethanol (30 s), 95\% ethanol (30 s), 100\% ethanol $(2 \times 60 \mathrm{~s})$, and Xylene (30 s).

Then, the stained slides were placed on the modular stage of the Leica LMD6000 (Leica Biosystems) within $20 \mathrm{~min}$ after drying for $5 \mathrm{~min}$ in the hood. Optimal visualizations were got by adjusting the illumination contrast and brightness. Before LCM, $30 \mu$ RLT lysis buffer (Qiagen, Courtaboeuf, France) or IP lysis buffer was added to the cap of a 200- $\mu$ l collection tube which was set onto the microscope. Using the drawing tools supplied by the system, the seminiferous tubule peripheral cell layers, mainly composed of SCs, spermatogonia, and early-stage spermatocytes, were outlined along the basement membrane on the manipulating screen. Then the outlined areas were microdissected from the tubules using a laser 


\section{Cellular Physiology Cell Physiol Biochem 2018;46:253-268 and Biochemistry Published online: March 27, $2018 \quad$\begin{tabular}{l|l} 
DOI:10.1159/000488427 2018 The Author(s). Published by S. Karger AG, Basel \\
www.karger.com/cpb
\end{tabular}}

Xu et al.: MiR-142-3p Inhibits TGF- 33 in BTB Regulation

spot of $15-\mu \mathrm{m}$ diameter and pulse duration of $5 \mathrm{~ms}$, followed by an inspection under the microscope for reconfirmation. The LCM-derived samples were divided into 3 groups depending on different seminiferous stages (stage VII-VIII, IX-III, and IV-VI). Approximately 50 (for subsequent qPCR assay) or 250 tubules (for subsequent immunoblot assay) randomly selected from 3-4 sections were microdissected for each group. The LCM was completed within $1 \mathrm{~h}$ to avoid RNA degradation and the collected cell components were stored at $-80^{\circ} \mathrm{C}$ until RNA or protein extraction.

RNA extraction, quality assessment, reverse transcription, and quantitative real-time PCR ( $q$ PCR)

The LCM-derived samples, or miRNA-transfected SC lysate, or agomir-treated testis homogenate were thawed on ice and total RNA were extracted using the RNeasy Plus Kit(Qiagen) according to the manufacturer's instructions, followed by DNase I (Qiagen) treatment to minimize genomic DNA contamination. The quantity and amount of the RNA was assessed by the Nanodrop ND2000 (Thermo Scientific, Rockford, AL, USA). Single-strand cDNAs were synthesized from total RNA of each sample ( $0.3 \mu \mathrm{g}$ for the LCM-derived samples and $1 \mu \mathrm{g}$ for SC or testis samples) using iScript cDNA Synthesis kit (Bio-Rad Laboratories, Hercules, CA, USA). Real-time PCR analysis was performed using the cDNA equivalent of $1.5 \mathrm{ng}$ total RNA with the QuantiFast SYBR Green PCR Kit (Qiagen) or miScript SYBR Green PCR Kit (Qiagen). An ABI Prism 7500 Real-Time PCR system (Applied Biosystems, Foster City, CA, USA) was applied with the cycling condition of $95^{\circ} \mathrm{C}$ for $10 \mathrm{~min}, 40 \mathrm{cycles}$ of $95^{\circ} \mathrm{C}$ for $15 \mathrm{sec}$, and $60^{\circ} \mathrm{C}$ for $1 \mathrm{~min}$, followed by a dissociation step. Relative expressions of different genes were calculated by the method of $\Delta \Delta C_{t^{*}}$ The primer sequences used were as follows: Lgl2 (forward: 5'-caaatcctcattggctacag-3', reverse: 5'-cggaccactggcagtggctg-3'), TGF- $\beta 3$ (forward: 5'cataggtggcaagaatctgc-3', reverse: 5'-gaacattttccagtatgtct-3'), miR-142-3p (forward: 5'-gtcgtatccagtgcaggg-3', reverse: 5'-cgacgtgtagtgtttccta-3'), with GAPDH or U6 served as the reference gene for detection of mRNAs or miRNAs, respectively.

\section{Statistical analysis}

Data from TER and Na-F permeability assay, immunoblot, BTB integrity assay, luciferase reporter assay, and qPCR in this study were analyzed by GB-STAT statistical software (version 7.0, Dynamic Microsystems, Silver Spring, MD, USA). Statistical significance between groups was analyzed with t-test or one-way ANOVA followed by a two-tailed Dunnett's test. All the results mentioned herein were representative of at least three independent experiments using different mature SD rats or SCs isolated from different batches of 20-day-old SD rats.

\section{Results}

MiR-142-3p inhibits the TGF- $\beta 3$-induced barrier function decrease in primary cultured SCS

Due to the involvement of miR-142-3p in TGF- $\beta$ signaling [26-28], we investigated the effects of miR-142-3p activation on the TGF- $\beta 3$-induced SC barrier function breakdown in vitro. In primarily cultured SCs, a $24 \mathrm{~h}$-treatment of TGF- $\beta 3$ at $3 \mathrm{ng} / \mathrm{ml}$ led to a significant TJ barrier decrease, which was reflected by the TER value decrease by $\sim 40 \%$ (Fig. $1 \mathrm{~A}$ ) and Na-F permeability increase by $\sim 30 \%$ (Fig. 1B). Conversely, with a transfection efficiency of more than $90 \%$ as indicated by siGLO red (Fig. 1E inset), miR-142-3p mimic led to a slightly but statistically significant TER value elevation (Fig. 1A). Moreover, the impairment of TGF- $\beta 3$ on TJ barrier assembly could not be detected in the miR-142-3p transfected SCs as in the negative mimic control (Fig. $1 \mathrm{~A}$ and $\mathrm{B}$ ). In order to explore mechanisms of the restoration of miR-142-3p on TGF- $\beta 3$-induced SC barrier impairment, we checked the activation of Cdc42, which had been proved previously to be a crucial regulatory component in the TGF- $\beta 3$ mediated TJ fibrils disruption between SCs [12], by immunoprecipitating the activated GTPbound form of Cdc42 using a Cdc42-GTP specific antibody. We found that comparing with the increasing Cdc4 2 activity after TGF- $\beta 3$ treatment in the control, there was no significant change in the Cdc42-GTP level in response to TGF- $\beta 3$ in miR-142-3p transfected SCs (Fig. $1 \mathrm{C}$ and D). Likewise, the down-regulation of TJ protein occludin caused by TGF- $\beta 3$ reflected by immunoblot and immunofluorescence analysis also could not be observed in the miR142-3p transfected group. Instead, the activation of miR-142-3p in SCs resulted in a slight 
Fig. 1. The impairing effect of TGF- $\beta 3$ on SC barrier function in vitro was inhibited by miR-142-3p. (A and B) Effects of TGF- $\beta 3$ on the barrier function of SCs transfected with miR-negative control (NC) mimic or miR-142-3p mimic reflected by the TER value (A) or Na-F permeability (B) across the epithelium. The permeability of Na-F in the miR-NC mimic group on day 3 was arbitrarily set at $100 \%$. (C) Immunoprecipitation and immunoblot analysis to assess the levels of GTPbound form of Cdc42, total Cdc42 and occludin in SC lysates prepared on day 6 after TGF- $\beta 3$ treatment for $24 \mathrm{~h}$ with GAPDH serving as a loading control. (D) A histogram summarizing the result shown in $\mathrm{C}$ after each data point was normalized against GAPDH. Protein level of the miR-NC group was arbitrarily set at 1. (E) Immunofluorescence to observe the distribution of occludin at cell junctions with Alexa Fluor 488-conjugated secondary antibody (green). Cell nuclei were stained with DAPI (blue). The inset indicated the transfection ef-

ficiency of siGLO (red). Scale bars $=25 \mu \mathrm{m}$. (F) Immunoblot analysis of T $\beta R I$ after miR-142-3p transfection with GAPDH serving as a loading control. (G) A histogram summarizing the result shown in $\mathrm{F}$ after each data point was normalized against GAPDH. Protein level of the miR-NC group was arbitrarily set at 1 . Each bar refers to the mean \pm SD of $n=3$ independent experiments using SCs cultured from different batches of 20 d-old SD rats. ${ }^{*} \mathrm{P}<0.05,{ }^{*} \mathrm{P}<0.01$, compared with the miR-NC mimic group. N.S., no significant difference.

increase in occludin level (Fig. 1C, D and E). Since miR-142-3p has been reported to target the TGF- $\beta$ type I receptor (T $\beta$ RI) [28], we analyzed the protein level of T $\beta$ RI in cultured SCs after miR-142-3p transfection but revealed no significant changes (Fig. 1F and G).

MiR-142-3p antagonizes the BTB integrity impairment caused by TGF- $\beta 3$ in vivo

Based on the findings in the cultured SC epithelium as above, we next sought to examine whether miR-142-3p could exert similar effect on the BTB integrity in vivo using biotin as the 


\section{Cellular Physiology and Biochemistry}

Fig. 2. Antagonism of miR-142-3p on the TGF- $\beta 3$-induced BTB disruption. (A) BTB integrity assay in vivo. The distribution of biotin as the indicator was observed by Alexa Fluor 568-conjugated streptavidin (red) with cell nuclei stained with DAPI (blue). Testis from rats treated with $\mathrm{CdCl}_{2}$ were used as the positive control of BTB disruption, which was indicated by the diffusion distance of biotin from the epithelium basement to the tubule lumen. Scale bar=60 $\mu \mathrm{m}$, applying to all micrographs in A. (B) A histogram illustrating results shown in $\mathrm{A}$. The biotin permeability was semi-quantified by calculating the ratio of diffusion distance and the average radius of a seminiferous tubule. Each bar refers to the mean \pm SD of at least 60-80 tubules randomly selected from 3-4 rats in one group. ${ }^{* *} \mathrm{P}<0.01$. N.S., no significant difference. (C) A histogram

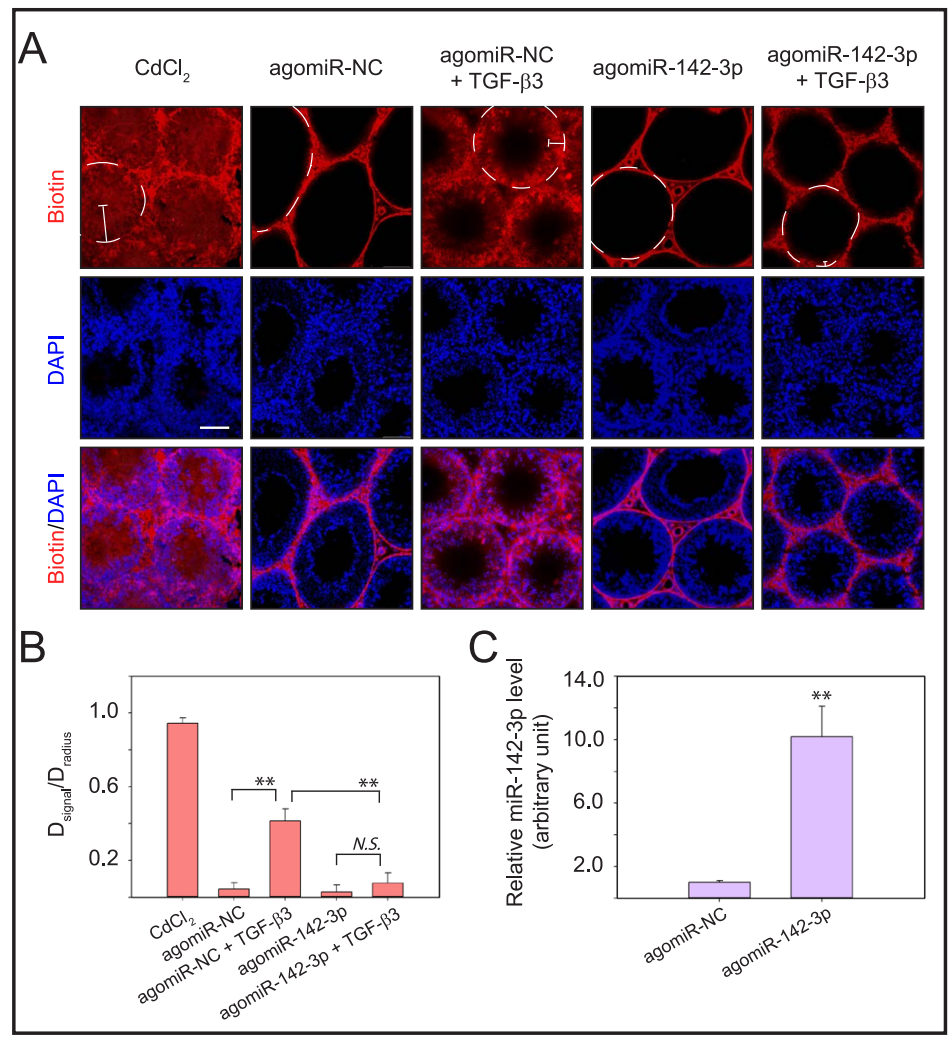
summarizing the result of qPCR in detecting the level of miR-142-3p after in vivo treatment of agomiRNAs, which was expressed as a relative index normalized against $\mathrm{U} 6 . * * \mathrm{P}<0.01$.

tracer. After consecutive administrations of agomiR-NC and recombinant TGF- $\beta 3$ (or vehicle PBS) in the rat testis, the signal of biotin permeated from the seminiferous tubule basement into the tubule lumen for an obviously further distance (about $40 \%$ of the tubule radius) in the TGF- $\beta 3$ group than in the PBS control, which signified the BTB integrity impairment (Fig. 2A and B). As anticipated, in the agomiR-142-3p administered rat testes, the following TGF- $\beta 3$ treatment could not arouse significant BTB function compromise, indicated by the distinct circle of biotin at the tubule basement (Fig. 2A and B). Herein, the testis lysates were acquired to evaluate the relative level of miR-142-3p by qPCR to confirm the effect of agomiR administration via intratesticular injection (Fig. 2C). Afterwards, the TJ protein occludin was detected by immunoblot and immunofluorescence, which displayed a declined expression after TGF- $\beta 3$ treatment in the agomiR-NC group (Fig. 3A and B). And consistent with the BTB integrity assay and the in vitro experiment, the agomiR-142-3p administration not only elevated the occludin level significantly, but also suppressed the down-regulation of occludin by TGF- $\beta 3$ (Fig. 3). These observations confirmed the antagonism of miR-142-3p on the BTB impairment caused by TGF- $\beta 3$.

\section{MiR-142-3p reduces Lgl2 protein level by targeting at Lgl2-3'UTR}

To uncover the potential mechanism underlying the inhibition of miR-142-3p on TGF- $\beta 3$-induced BTB impairment, the conceivable targets of miR-142-3p were predicted by computer-aided algorithms in Targetscan (http://www.targetscan.org) and Starbase (http://starbase.sysu.edu.cn/), of which the theoretical binding of miR-142-3p to the 3'-UTR of Lgl2 transcript aroused our interests due to the previously reported role of Scribble/Lgl2/ Dlg1 polarity complex in BTB regulation [32]. Therefore, mutations were generated on the putative binding site before a luciferase reporter assay to verify the binding specificity (Fig. 4A). The recombined luciferase reporter vector containing Lgl2-3'-UTR sequence (WT or 


\section{Cellular Physiology and Biochemistry}

Cell Physiol Biochem 2018;46:253-268

\begin{tabular}{l|l}
\hline DOI:10.1159/000488427 & (c) 2018 The Author(s). Published by S. Karger AG, Basel
\end{tabular}

Xu et al.: MiR-142-3p Inhibits TGF- $\beta 3$ in BTB Regulation
Fig. 3. MiR-142-3p inhibits the down-regulation of occludin caused by recombinant TGF- $\beta 3$ in rat testis. (A) Immunoblot analysis of occludin with GAPDH serving as a loading control. Testis lysates were prepared $24 \mathrm{~h}$ after TGF- $\beta 3$ injection using tissue located within $4 \mathrm{~mm}$ from the injection site. (B) A histogram illustrating the result shown in A after each data point was normalized against GAPDH. Occludin level of the agomiR-NC group was arbitrarily set at 1 . Each bar refers to the mean \pm SD of $\mathrm{n}=4-5$ rats. ${ }^{* *} \mathrm{P}<0.01$, compared with the agomiR-NC group. N.S., no significant difference. (C) Immunofluorescence analysis using cryosections of testis to examine the localization of occludin (red). Cell nuclei were stained with DAPI (blue). Scale bar=60 $\mu \mathrm{m}$, which applies to all micrographs in $\mathrm{C}$.

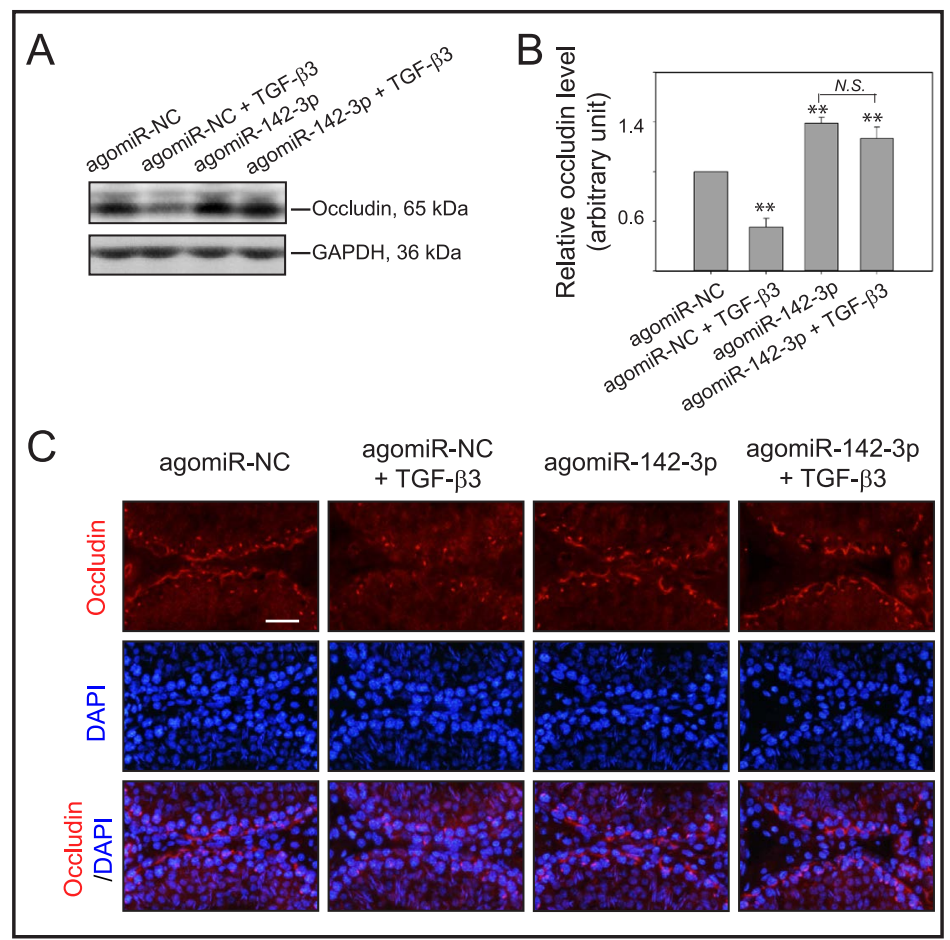

Fig. 4. MiR-142-3p downregulates $\mathrm{Lgl} 2$ expression by directly targeting Lgl2-3'UTR. (A) The binding site of miR-142-3p on Lgl2-3'UTR predicted by Targetscan and Starbase and the luciferase reporter in conjugation with either the wild-type (WT) or mutant (MUT) sequence of Lgl23'UTR constructed using pMIRREPORT vector. Nucleotides in red referred to the mutation sites. (B) Dual luciferase reporter assay in HEK293 cells. The luciferase activity of each group was calculated by normalizing the firefly luciferase activity to renilla luciferase activity. The value of the control mimic group was arbitrarily set at 1. (C) Immunoblot analyzing Lgl2 protein level in cultured SCs transfected with mimic or inhibitor of miR-142-3p with GAPDH serving as a loading control. (D) A histogram summarizing the result of $\mathrm{C}$ after each data point was normalized against GAPDH. Lgl2 level of the non-transfecting control group was arbitrarily set at 1. (E) A histogram illustrating the result of qPCR in detecting the relative level of Lgl2 mRNA after transfecting SCs with mimic or inhibitor of miR-142-3p, which was expressed as a relative index normalized against GAPDH. Each bar refers to the mean \pm SD of $n=3$ independent experiments. ${ }^{* *} \mathrm{P}<0.01$. N.S., no significant difference.

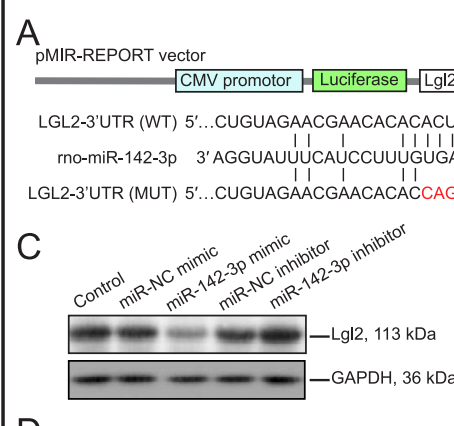

B

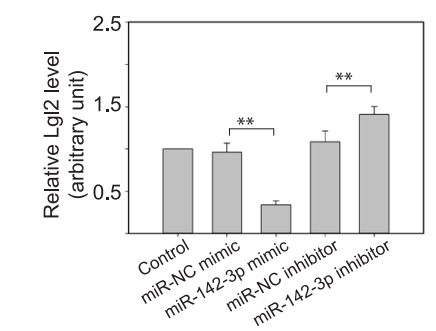

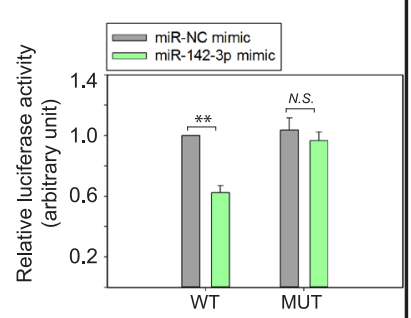

E

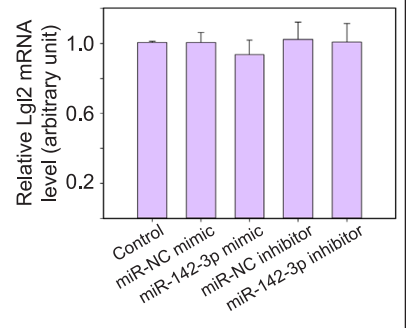


Fig. 5. MiR-142-3p inhibits $\mathrm{Lgl} 2$ expression induced by TGF- $\beta 3$. (A) Immunoblot analyzing Lgl2 level in TGF- $\beta 3$-treated SCs with GAPDH serving as a loading control. (B) A histogram summarizing the result of $A$ after each data point was normalized against GAPDH. Lgl2 level of the control group was arbitrarily set at 1 . (C) Immunoblot analyzing Lgl2 level after TGF- $\beta 3$ treatment in miR142-3p mimic-transfected SCs with GAPDH serving as a loading control. (D) A histogram summarizing the result of $\mathrm{C}$ after each data point was normalized against GAPDH. Lgl2 level of the miR-NC mimic group was arbitrarily set at 1. (E) A histogram illustrating the result of qPCR in detecting the relative level of Lgl2 mRNA using SCs treated in the same way as C, which was expressed as a relative index normalized against GAPDH. ${ }^{* *} \mathrm{P}<0.01$. N.S., no significant dif-

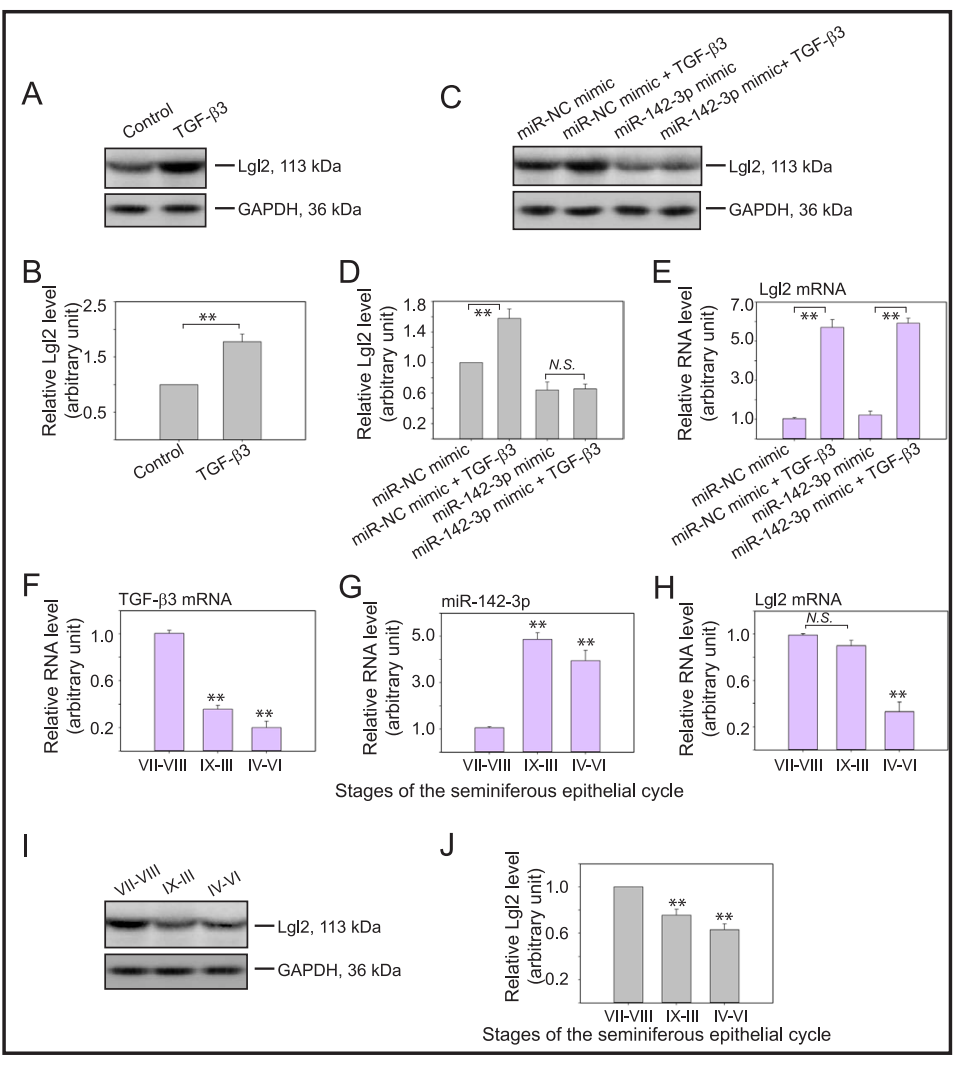
ference. (F, G, and H) Histograms illustrating the result of qPCR in detecting the relative level of TGF- $\beta 3$ mRNA (F), miR-142-3p (G), and Lgl2 mRNA (H) using LCM-derived components from different stages of seminiferous tubules, which was expressed as a relative index normalized against GAPDH or U6. (I) Immunoblot analyzing Lgl2 level using LCM-derived samples with GAPDH serving as a loading control. (J) A histogram summarizing the result of I after each data point was normalized against GAPDH. Lgl2 level of stage VII-VIII was arbitrarily set at $1{ }^{* *} \mathrm{P}<0.01$, compared with stage VII-VIII. N.S., no significant difference.

MUT) were co-transfected with miR-142-3p mimic (or miR-NC mimic) into HEK293 cells. The result showed that overexpression of miR-142-3p reduced the luciferase activity by about $40 \%$ when the reporter gene was recombined with Lgl2-3'-UTR-WT. In contrast, mutations on the putative binding site of Lgl2-3'-UTR significantly abrogated the suppression of luciferase activity induced by miR-142-3p (Fig. 4B). Moreover, when the mimic or inhibitor of miR-142-3p was transfected into cultured SCs, the level of Lgl2 protein was significantly reduced or induced (Fig. 4C and D), respectively, whereas with no obvious changes in mRNA level of Lgl2 (Fig. 4E). These findings suggest the direct binding of miR-142-3p to Lgl2-3'UTR and the post-translational regulation of Lgl2 expression by miR-142-3p in SCs.

MiR-142-3p inhibits the Lgl2 protein level increment induced by TGF- $\beta 3$ in cultured SCs

In order to determine whether it was the negative regulation of $\mathrm{Lgl} 2$ expression by miR-142-3p that reversed the TGF- $\beta 3$-induced BTB impairment, we first analyzed the level of Lgl2 in SCs after TGF- $\beta 3$ treatment and were delightfully surprised to find a significant increase (Fig. 5A and B). However, after miR-142-3p transfection, the treatment of TGF- $\beta 3$ could not elicit the same alteration in Lgl2 protein level (Fig. 5 C and D), but its mRNA transcript maintained an obviously higher level as compared with the control (Fig. $5 \mathrm{E}$ ). These observations strongly suggest that Lgl2 might be a crucial factor during BTB dynamics regulated by TGF- $\beta 3$, which was negatively controlled by miR-142-3p during the seminiferous epithelial cycle. 
Fig. 6. Lgl2 knockdown partially antagonizes the TGF- $\beta 3$-induced SC barrier function decrease. (A and B) Effects of TGF- $\beta 3$ on the barrier function of SCs after Lgl2 siRNA transfection, reflected by the TER value (A) or Na-F permeability (B) across the epithelium. The permeability of Na-F in the control siRNA group on day 3 was arbitrarily setat $100 \%$. (C) Immunoprecipitation and immunoblot to analyze Cdc42GTP, total Cdc42 and occludin in Lgl2silenced SCs after TGF- $\beta 3$ treatment with GAPDH as a loading control. (D) Histograms summarizing the result shown in $\mathrm{C}$ after each data was normalized against GAPDH. Protein level of the control siRNA group was arbitrarily set at 1 . Each bar refers to the mean $\pm S D$ of $n=3$ independent experiments. Immunofluorescence to observe occludin distribution at cell junctions with Alexa Fluor 488-conjugated secondary antibody (green). Cell nuclei were stained with DAPI (blue). The inset indicated the transfection efficiency of siGLO (red). Scale bars $=25 \mu \mathrm{m}$. ${ }^{*} \mathrm{P}<0.05$, $* * \mathrm{P}<0.01$, compared with the control siRNA group. ${ }^{\circ} \mathrm{P}<0.05,{ }^{\circ} \mathrm{P}<0.01$, compared with the Lgl2 siRNA group. ${ }^{\#} \mathrm{P}<0.01$, compared with the Ctrl siRNA+TGF- $\beta 3$ group.

The stage-specific and correlated expression of TGF- $\beta 3$, miR-142-3p, and Lgl2 during the seminiferous epithelial cycle

According to its role during BTB restructuring at late stage VII through early stage VIII when preleptotene spermatocytes are traversing the BTB in the rat testis, TGF- $\beta 3$ has been previously proved to put up a stage-specific expression by morphological method [39]. In this study, we applied LCM to separate SC components of different seminiferous stages to explore the stage specificity and the expression correlations between TGF- $\beta 3$, miR-142$3 p$, and Lgl2 (Fig. 5F). The result of qPCR using lysate from LCM-derived samples showed a completely contrary expression pattern between TGF- $\beta 3$ mRNA and miR-142-3p, with the former peaked at stage VII-VIII when the latter reached its bottom, indicating opposite roles of the two molecules in regulating BTB dynamics (Fig. 5F and G). For the Lgl2 expression, the mRNA level showed no significant difference between stage IX-III and stage VII-VIII in spite of the TGF- $\beta 3$ dropping after stage VIII. However, an obvious decrease of Lgl2 protein level after stage VIII using the same samples was discovered (Fig. 5I and J), comparing with the lagging decline of its mRNA transcript at stage IV-VI (Fig. 5H). These results not only validate the findings from the in vitro experiment, but also demonstrate a dynamic regulation of Lgl2 by TGF- $\beta 3$ and miR-142-3p during the seminiferous cycle. 


\section{Cellular Physiology Cell Physiol Biochem 2018;46:253-268 \begin{tabular}{l|l|l} 
DOI:10.1159/000488427 & a 2018 The Author(s). Published by S. Karger AG, Basel \\
www.karger.com/cpb
\end{tabular} \\ Xu et al.: MiR-142-3p Inhibits TGF- $\beta 3$ in BTB Regulation}

Lgl2 knockdown partially antagonizes the TGF- $\beta 3$-induced SC barrier function decrease in vitro

Lgl2 is the dominant form of the four mammalian homologs of Lgl in the testis and constituent of the Scribble polarity complex, which has previously been shown to participate in the regulation of BTB dynamics and spermatid polarity [32]. Herein, to further clarify the role of Lgl2 during TGF- $\beta 3$-induced SC barrier function decrease and to explore the significance of Lgl2 regulation by miR-142-3p during BTB dynamics, we silenced Lgl2 in cultured SCs by about 70\% (Fig. 6C and D) with siRNA, followed by the TGF- $\beta 3$ treatment. Although the barrier function assays still found a decrease in TER value $(\sim 15 \%)$ and an increase in Na-F permeability $(\sim 20 \%)$ after TGF- $\beta 3$ treatment in the Lgl2-silenced $\mathrm{SCs}$, the variation extent was greatly discounted versus the case in control siRNA group ( $\sim 50 \%$ in TER value and $\sim 40 \%$ in Na-F permeability, respectively), which indicated a partial antagonism of TGF- $\beta 3$-induced BTB disruption by Lgl2 silencing (Fig. 6A and B). The following immunoprecipitation analysis after TGF- $\beta 3$ treatment showed similar Cdc42 activity promotion in the Lgl2-silenced group as the control siRNA group, prompting Lgl2 and Cdc42 as two irrelevant downstream effectors of TGF- $\beta 3$ in SC function regulation (Fig. 6C and D). Moreover, an induction of occludin expression was further confirmed after Lgl2 knockdown, intriguingly with no significant descending tendency even when the cells were treated with TGF- $\beta 3$, which was in distinct contrast with the case in the control siRNA group (Fig. 6C, D and E). The above findings demonstrated the participation of Lgl2 in BTB function regulation by TGF- $\beta 3$, which might partially account for the antagonism of miR-142-3p on TGF- $\beta 3$-induced BTB function impairment.

\section{Discussion}

During spermatogenesis, the entry of spermatocytes into the apical compartment of the seminiferous epithelium involves breakdown and reassembling of the BTB apparatus [40]. These events are crucial to the barrier function of the SC epithelium and further development of the gemate, and are elaborately coordinated by cytokines, androgens, and estrogens secreted by testicular cells. The disruptive effect of TGF- $\beta 3$ on BTB was discovered almost two decades ago [41], followed by a series of studies investigating the underlying molecular mechanisms. Overexpression of TGF- $\beta 3$ in primary SCs was revealed to perturb the TJ barrier by reducing occludin, $\mathrm{N}$-cadherin, and zonula occludens-1 (ZO-1), simultaneously with the activation of p38 MAPK and ERK signaling pathways [39]. Endocytosis assay in cultured SCs demonstrated an increased clathrin-mediated internalization of occludin, junctional adhesion molecule-A (JAM-A), and N-cadherin caused induced by TGF- $\beta 3$ [10]. Further study overexpressing the dominant-negative mutant of Cdc42 in SCs was shown to block the TGF- $\beta 3$-induced junction protein endocytosis and redistribution of TJ proteins such as CAR and ZO-1 [12]. In the present study, we observed similar results after TGF- $\beta 3$ administration, as reflected by the disrupted barrier function both in cultured SCs and in the rat testis, accompanied with a decreased occludin level and an increased GTP-bound form of Cdc42.

MiRNAs are short non-coding RNAs that control gene expression by targeting mRNAs for degradation or translation inhibition, determining cell functions and cell fates under normal or pathological conditions [42]. To address the potential mechanism of BTB function regulation on the post-transcriptional level which was seldom reported, we explored the influence of miR-142-3p on the BTB impairment induced by TGF- $\beta 3$ due to its known functions in TGF$\beta 3$-related signaling in various cell types, including targeting directly at T $\beta R 1$ in NSCLC [28]. As we expected, miR-142-3p was clearly confirmed to block the BTB permeability elevation caused by TGF- $\beta 3$. However, we did not observe significant variation in the T $\beta$ R 1 protein level after miR-142-3p treatment in SCs, implying diverse action mechanisms of miR-142-3p 


\section{Cellular Physiology Cell Physiol Biochem 2018;46:253-268 \begin{tabular}{l|l|l} 
and BiOChemistry & $\begin{array}{l}\text { DOI:10.1159/000488427 } \\
\text { Published online: March 27, } 2018\end{array}$ & $\begin{array}{l}\text { C } 2018 \text { The Author(s). Published by S. Karger AG, Basel } \\
\text { www.karger.com/cpb }\end{array}$
\end{tabular}}

Xu et al.: MiR-142-3p Inhibits TGF- $\beta 3$ in BTB Regulation

in non-tumor cells versus tumor cells. It was known that one miRNA could target various of genes to form a complicated regulation network [43]. Herein, we identified Lgl2 as a novel target of miR-142-3p. Its unchanged mRNA levels in contrast with the varied protein levels after miR-142-3p mimic or inhibitor treatments argues that the binding of miR-142-3p to Lgl2-3'-UTR was for translation inhibiting rather than mRNA degradation. It should be noted that, before the TGF- $\beta 3$ treatment on day 5 in the in vitro experiment, SCs transfected with miR-142-3p began to put up a better barrier function versus the negative control, indicating the involvement of Lgl2 during BTB function regulation in the absence of TGF- $\beta 3$.

The mammalian Lgl proteins are WD-repeats-containing proteins which often function in coordinating protein-protein interactions [44, 45]. In epithelial cells, Lgl exerts antagonistic interactions with Par3/6 complex in regulating cell polarity and TJ formation [30]. The role of Lgl2 in BTB function regulation was first described while exploring the function of Scribble/ Dlg1/Lgl2 complex during spermatogenesis, which revealed an increased spermatid polarity loss caused by filamentous actin reorganization and $\beta 1$-integrin decreasing after simultaneous knockdown of Scribble/Dlg1/Lgl2 in the rat testis. Importantly, the solely knockdown of Lgl2 was shown to increase the occludin distribution at the BTB and raise up the TER value in cultured SCs [32], coinciding with what we observed herein regardless of the presence of TGF- $\beta 3$. In the current study, we also detected a surge in Lgl2 after TGF- $\beta 3$ treatment in SCs. The following attenuated impairing effect of TGF- $\beta 3$ on the TJ barrier in Lgl2-silenced SCs prompted the contribution of Lgl2 during the BTB disruption induced by TGF- $\beta 3$. However, the barrier function was not completely restored by Lgl2 silencing despite of the increased occludin level, indicating the induced Lgl2 and reduced occludin only part of the factors affected by TGF- $\beta 3$ in SCs. It also should be noted that the activation of Cdc42 still existed after TGF- $\beta 3$ treatment in Lgl2-silenced cells. Differently, in miR-142-3p transfected SCs, TGF- $\beta 3$ could not elicit Cdc42 activation any more. Therefore, although our results show that Lgl 2 was the direct target of miR-142-3p, it might not be the only signaling molecule that regulated by miR-142-3p during BTB regulation. Moreover, since Lgl has been reported previously to suppress the interaction between Cdc42 and the aPKC-Par6 complex for inhibition of the apical Par complex activity [46], further studies should be carried out to investigate the discrepant role of Lgl2 in Cdc42 activity controlling and the mechanisms by which Cdc42 function was mediated by miR-142-3p during BTB function regulation.

The seminiferous epithelial cycle was propelled by an array of signaling molecules and pathways which were precisely regulated according to the stage transitions. In order to study the stage-specific gene expression that related to BTB dynamics, we applied LCM to separate SC components of different seminiferous stages, which had been shown to be a valuable technique to investigate the stage-specific response following toxicant exposure in the testis $[38,47]$. In this study, we focused on the expression level of TGF- $\beta 3$, miR- $142-3 p$, and Lgl2 throughout the seminiferous cycle to elucidate the possible relationships between these factors during stage transitions. Consistent with the previous report using morphological techniques [39], TGF- $\beta 3$ showed the highest mRNA expression at stage VII-VIII, which, together with the lowered level of miR-142-3p, might make a good explanation for the high level of Lgl2 at the same stage period. However, after the preleptotene spermatocyte complete traversing the BTB at stage VIII, the mRNA level of Lgl2 did not decrease immediately as TGF- $\beta 3$ at stage IX. At this time point, the surge in miR-142-3p might play a key role in reducing the Lgl2 protein through post-translational regulation, which then recovered the protein level of occludin. This deduced regulation pattern also agreed with the stage-specific expression of occludin that always presented an obviously weakened signal at stage VIII in morphological assays [48]. Whereas, the samples of LCM in our study could not completely remove the disturbance of spermatogonia and early-stage spermatocytes due to the irregular shape of the SC, though the microdissection was performed adjacent to the basement of the seminiferous tubule. Therefore, more advanced techniques and more profound studies on the molecular level are needed to annotate these observations. 


\section{Cellular Physiology Cell Physiol Biochem 2018;46:253-268 \begin{tabular}{l|l} 
and Biochemistry Pul:10.1159/000488427 & $\begin{array}{l}\text { (c) } 2018 \text { The Author(s). Published by S. Karger AG, Basel } \\
\text { www.karger.com/cpb }\end{array}$
\end{tabular} Xu et al.: MiR-142-3p Inhibits TGF- $\beta 3$ in BTB Regulation}

\section{Conclusion}

In summary, the current study demonstrated the counteraction of miR-142-3p in TGF$\beta 3$-induced BTB impairment and identified Lgl2 3'-UTR as the direct target of miR-142$3 p$. The stage-specific regulation of Lgl2 by miR-142-3p and TGF- $\beta 3$ might improve our understanding of the mechanisms of the BTB dynamics and the seminiferous epithelium cycle progression.

\section{Acknowledgements}

This work was supported by the National Natural Science Foundation of China (81370756) to WS.

\section{Disclosure Statement}

The authors declare that they have no Disclosure Statement.

\section{References}

1 Cheng CY, Mruk DD: The blood-testis barrier and its implications for male contraception. Pharmacol Rev 2012;64:16-64.

-2 Walsh SV, Hopkins AM, Nusrat A: Modulation of tight junction structure and function by cytokines. Adv Drug Deliv Rev 2000;41:303-313.

-3 Xia W, Mruk DD, Lee WM, Cheng CY: Cytokines and junction restructuring during spermatogenesis--a lesson to learn from the testis. Cytokine Growth Factor Rev 2005;16:469-493.

-4 Marchiando AM, Graham WV, Turner JR: Epithelial barriers in homeostasis and disease. Annu Rev Pathol 2010;5:119-144.

5 Roberson ED, Bowcock AM: Psoriasis genetics: breaking the barrier. Trends Genet 2010;26:415-423.

6 Capaldo CT, Nusrat A: Cytokine regulation of tight junctions. Biochim Biophys Acta 2009;1788:864-871.

7 Lui WY, Lee WM, Cheng CY: TGF-betas: their role in testicular function and Sertoli cell tight junction dynamics. Int J Androl 2003;26:147-160.

8 Lui WY, Wong CH, Mruk DD, Cheng CY: TGF-beta3 regulates the blood-testis barrier dynamics via the p38 mitogen activated protein (MAP) kinase pathway: an in vivo study. Endocrinology 2003;144:11391142.

-9 Yan HH, Mruk DD, Lee WM, Cheng CY: Blood-testis barrier dynamics are regulated by testosterone and cytokines via their differential effects on the kinetics of protein endocytosis and recycling in Sertoli cells. FASEB J 2008;22:1945-1959.

-10 Xia W, Wong EW, Mruk DD, Cheng CY: TGF-beta3 and TNFalpha perturb blood-testis barrier (BTB) dynamics by accelerating the clathrin-mediated endocytosis of integral membrane proteins: a new concept of BTB regulation during spermatogenesis. Dev Biol 2009;327:48-61.

11 Massague J, Gomis RR: The logic of TGFbeta signaling. FEBS Lett 2006;580:2811-2820.

12 Wong EW, Mruk DD, Lee WM, Cheng CY: Regulation of blood-testis barrier dynamics by TGF-beta3 is a Cdc42-dependent protein trafficking event. Proc Natl Acad Sci U S A 2010;107:11399-11404.

-13 Braun RE: Post-transcriptional control of gene expression during spermatogenesis. Semin Cell Dev Biol 1998;9:483-489.

14 Papaioannou MD, Nef S: MicroRNAs in the testis: building up male fertility. J Androl 2010;31:26-33.

15 Papaioannou MD, Pitetti JL, Ro S, Park C, Aubry F, Schaad O, Vejnar CE, Kuhne F, Descombes P, Zdobnov EM, McManus MT, Guillou F, Harfe BD, Yan W, Jegou B, Nef S: Sertoli cell Dicer is essential for spermatogenesis in mice. Dev Biol 2009;326:250-259. 


\section{Cellular Physiology Cell Physiol Biochem 2018;46:253-268 \begin{tabular}{ll|l} 
and Biochemistry Published online: March 27, 2018 & $\begin{array}{l}\text { (c) } 2018 \text { The Author(s). Published by S. Karger AG, Basel } \\
\text { www.karger.com/cpb }\end{array}$
\end{tabular}}

Xu et al.: MiR-142-3p Inhibits TGF- $\beta 3$ in BTB Regulation

-16 Papaioannou MD, Lagarrigue M, Vejnar CE, Rolland AD, Kuhne F, Aubry F, Schaad O, Fort A, Descombes P, Neerman-Arbez M, Guillou F, Zdobnov EM, Pineau C, Nef S: Loss of Dicer in Sertoli cells has a major impact on the testicular proteome of mice. Mol Cell Proteomics 2011;10:M900587MCP900200.

$\checkmark 17$ Korhonen HM, Yadav RP, Da Ros M, Chalmel F, Zimmermann C, Toppari J, Nef S, Kotaja N: DICER regulates the formation and maintenance of cell-cell junctions in the mouse seminiferous epithelium. Biol Reprod 2015;93:139.

18 Neilson JR, Zheng GX, Burge CB, Sharp PA: Dynamic regulation of miRNA expression in ordered stages of cellular development. Genes Dev 2007;21:578-589.

19 Jin HL, Kim JS, Kim YJ, Kim SJ, Broxmeyer HE, Kim KS: Dynamic expression of specific miRNAs during erythroid differentiation of human embryonic stem cells. Mol Cells 2012;34:177-183.

20 Wang F, Wang XS, Yang GH, Zhai PF, Xiao Z, Xia LY, Chen LR, Wang Y, Wang XZ, Bi LX, Liu N, Yu Y, Gao D, Huang BT, Wang J, Zhou DB, Gong JN, Zhao HL, Bi XH, Yu J, Zhang JW: MiR-29a and miR-142-3p downregulation and diagnostic implication in human acute myeloid leukemia. Mol Biol Rep 2012;39:27132722.

21 Wu L, Cai C, Wang X, Liu M, Li X, Tang H: MicroRNA-142-3p, a new regulator of RAC1, suppresses the migration and invasion of hepatocellular carcinoma cells. FEBS Lett 2011;585:1322-1330.

22 MacKenzie TN, Mujumdar N, Banerjee S, Sangwan V, Sarver A, Vickers S, Subramanian S, Saluja AK: Triptolide induces the expression of miR-142-3p: a negative regulator of heat shock protein 70 and pancreatic cancer cell proliferation. Mol Cancer Ther 2013;12:1266-1275.

23 Qi X, Li J, Zhou C, Lv C, Tian M: MiR-142-3p Suppresses SOCS6 Expression and Promotes Cell Proliferation in Nasopharyngeal Carcinoma. Cell Physiol Biochem 2015;36:1743-1752.

24 Xu G, Wang J, Jia Y, Shen F, Han W, Kang Y: MiR-142-3p functions as a potential tumor suppressor in human osteosarcoma by targeting HMGA1 Cell Physiol Biochem 2014;33:1329-1339.

-25 Novotny GW, Belling KC, Bramsen JB, Nielsen JE, Bork-Jensen J, Almstrup K, Sonne SB, Kjems J, Rajpert-De Meyts E, Leffers H: MicroRNA expression profiling of carcinoma in situ cells of the testis. Endocr Relat Cancer 2012;19:365-379.

26 Kim D, Song J, Kim S, Kang SS, Jin EJ: MicroRNA-142-3p regulates TGF-beta3-mediated region-dependent chondrogenesis by regulating ADAM9- Biochem Biophys Res Commun 2011;414:653-659.

27 Kim K, Yang DK, Kim S, Kang H: MiR-142-3p is a regulator of the TGFbeta-mediated vascular smooth muscle cell phenotype. J Cell Biochem 2015;116:2325-2333.

28 Lei Z, Xu G, Wang L, Yang H, Liu X, Zhao J, Zhang HT: MiR-142-3p represses TGF-beta-induced growth inhibition through repression of TGFbetaR1 in non-small cell lung cancer. FASEB J 2014;28:2696-2704.

29 Lutzelschwab R, Klambt C, Rossa R, Schmidt O: A protein product of the Drosophila recessive tumor gene, 1 (2) giant gl, potentially has cell adhesion properties. EMBO J 1987;6:1791-1797.

-30 Yamanaka T, Horikoshi Y, Sugiyama Y, Ishiyama C, Suzuki A, Hirose T, Iwamatsu A, Shinohara A, Ohno S: Mammalian Lgl forms a protein complex with PAR-6 and aPKC independently of PAR-3 to regulate epithelial cell polarity. Curr Biol 2003;13:734-743.

31 Etienne-Manneville S: Scribble at the crossroads. J Biol 2009;8:104.

-32 Su W, Wong EW, Mruk DD, Cheng CY: The Scribble/Lgl/Dlg polarity protein complex is a regulator of bloodtestis barrier dynamics and spermatid polarity during spermatogenesis. Endocrinology 2012;153:60416053.

33 Russell LD, Saxena NK, Weber JE: Intratesticular injection as a method to assess the potential toxicity of various agents and to study mechanisms of normal spermatogenesis. Gamete Res 1987;17:43-56.

-34 Lu Y, Luo B, Li J, Dai J: Perfluorooctanoic acid disrupts the blood-testis barrier and activates the TNFalpha/ p38 MAPK signaling pathway in vivo and in vitro. Arch Toxicol 2016;90:971-983.

-35 Meng J, Holdcraft RW, Shima JE, Griswold MD, Braun RE: Androgens regulate the permeability of the bloodtestis barrier. Proc Natl Acad Sci U S A 2005;102:16696-16700.

-36 Jia X, Xu Y, Wu W, Fan Y, Wang G, Zhang T, Su W: Aroclor1254 disrupts the blood-testis barrier by promoting endocytosis and degradation of junction proteins via p38 MAPK pathway. Cell Death Dis 2017;8:e2823.

-37 Mruk DD, Cheng CY: An in vitro system to study Sertoli cell blood-testis barrier dynamics. Methods Mol Biol 2011;763:237-252.

-38 Catlin NR, Huse SM, Boekelheide K: The stage-specific testicular germ cell apoptotic response to low-dose $\mathrm{X}$-irradiation and 2, 5-hexanedione combined exposure. I: Validation of the laser capture microdissection method for qRT-PCR array application. Toxicol Pathol 2014;42:1221-1228. 


\section{Cellular Physiology Cell Physiol Biochem 2018;46:253-268 \begin{tabular}{l|l} 
DOI:10.1159/000488427 \\
and Biochemistry
\end{tabular} \begin{tabular}{l}
$\begin{array}{l}\text { O 2018 The Author(s). Published by S. Karger AG, Basel } \\
\text { www.karger.com/cpb }\end{array}$ \\
\cline { 2 - 3 }
\end{tabular} \\ $X u$ et al.: MiR-142-3p Inhibits TGF- $\beta 3$ in BTB Regulation}

39 Xia W, Mruk DD, Lee WM, Cheng CY: Differential interactions between transforming growth factor-beta3/ TbetaR1, TAB1, and CD2AP disrupt blood-testis barrier and Sertoli-germ cell adhesion. J Biol Chem 2006;281:16799-16813.

40 Russell L: Movement of spermatocytes from the basal to the adluminal compartment of the rat testis. Am J Anat 1977;148:313-328.

41 Lui WY, Lee WM, Cheng CY: Transforming growth factor-beta3 perturbs the inter-Sertoli tight junction permeability barrier in vitro possibly mediated via its effects on occludin, zonula occludens-1, and claudin-11. Endocrinology 2001;142:1865-1877.

-42 Bartel DP: MicroRNAs: target recognition and regulatory functions. Cell 2009;136:215-233.

-43 Friedman RC, Farh KK, Burge CB, Bartel DP: Most mammalian mRNAs are conserved targets of microRNAs. Genome Res 2009;19:92-105.

44 Klezovitch 0, Fernandez TE, Tapscott SJ, Vasioukhin V: Loss of cell polarity causes severe brain dysplasia in Lgl1 knockout mice. Genes Dev 2004;18:559-571.

45 Li D, Roberts R: WD-repeat proteins: structure characteristics, biological function, and their involvement in human diseases. Cell Mol Life Sci 2001;58:2085-2097.

46 Yamanaka T, Horikoshi Y, Izumi N, Suzuki A, Mizuno K, Ohno S: Lgl mediates apical domain disassembly by suppressing the PAR-3-aPKC-PAR-6 complex to orient apical membrane polarity. J Cell Sci 2006;119:2107-2118.

47 Campion SN, Sandrof MA, Yamasaki H, Boekelheide K: Suppression of radiation-induced testicular germ cell apoptosis by 2, 5-hexanedione pretreatment. III. Candidate gene analysis identifies a role for fas in the attenuation of X-ray-induced apoptosis. Toxicol Sci 2010;117:466-474.

-48 Morrow CM, Mruk D, Cheng CY, Hess RA: Claudin and occludin expression and function in the seminiferous epithelium. Philos Trans R Soc Lond B Biol Sci 2010;365:1679-1696. 